\title{
Calcium Carbonate Test Formation in the Ciliate Coleps
}

\author{
Rianna DiBartolo-Cordovano*, Carolyn Marks*, Annie Sprick* and Roni Kingsley* \\ *Department of Biology, University of Richmond
}

Coleps is a ciliate belonging to the class Prostomatea. These small barrel shaped organisms are best known by Zebrafish researchers as "twirlies", due to their characteristic form of motion. Coleps are seen as pests because they aggressively prey on Zebrafish larvae. To us however these organisms are fascinating, and may hold key information to the formation of calcium carbonate tests in a wide array of organisms. The genus Coleps are single celled organisms of ten different species [1]. They are typically $37-50 \mu \mathrm{m}$ long and $24-40 \mu \mathrm{m}$ wide at the middle [3]. Coleps are characterized by a calcium carbonate test of many armor-like plates which give it the appearance of a grape-in-a-barrel (fig. 1A). This plate morphology is species specific, but generally they represent four longitudinal girdles that taper near the anterior end of the organism [2]. Each plate is composed of multiple pieces through which cilia protrude and weave, running along the anterior posterior axis (refer to Fig. 1D). Daughter cells of dividing Coleps each receive one half the test (fig $1 \mathrm{~B}, \mathrm{C}$ ). The distal portion subsequently experiences calcification of a new test (fig. 1B, upper right of Coleps).

The mechanism by which Coleps forms the calcium carbonate test has been unclear. In most other calcifying organisms, several different types of cells are required in this process. Studying calcification in Coleps provides an opportunity to study all aspects of this process in a single cell. This study utilizes scanning and transmission electron microscopy to follow all stages of calcification in the formation of tests.

Samples were prepared by filtering $20 \mathrm{ml}$ of Coleps-containing fish tank water through a Swinny syringe assembly containing a $.45 \mu \mathrm{m}$ Durapore Membrane filter. The filtrate was set aside and used as the solvent for a $2.5 \%$ glut $1 \%$ OsO4 fix. After fixation samples were rinsed in water and dehydrated through a graded ethanol series. At this point samples were split for SEM and TEM. The SEM samples were dried using HDMS and sputter coated with a gold/palladium. TEM samples were embedded in Embed 812 resin utilizing capillary tubing. Coleps tend to dissociate during preparation procedures and do not pellet in resin, therefore they must be gathered in capillary tubing prior to embedding.

[1] Noland, Lowell E. A review of the Genus Coleps with Descriptions of Two New Species. Transactions of American Microscopical Society. Vol XLIV. No. 1. January 1925.

[2] Huttenlauch, Irm. SEM Study of the Skeletal Plates of Coleps Nolandi Kahl, 1930. Institut für Biologie III, Universität Tübingen. Protistologicia. T. XXI, fasc. 4 p.499-503. 1985.

[3] Serrano et. al. Cytological Observations on the Ciliate Coleps hirtus Nitzch, 1817: Vegetative Cell, Binary Fission and Conjugation. Acta Protozoologica. Vol. 24, No.2, p. 77-84. 1985. 

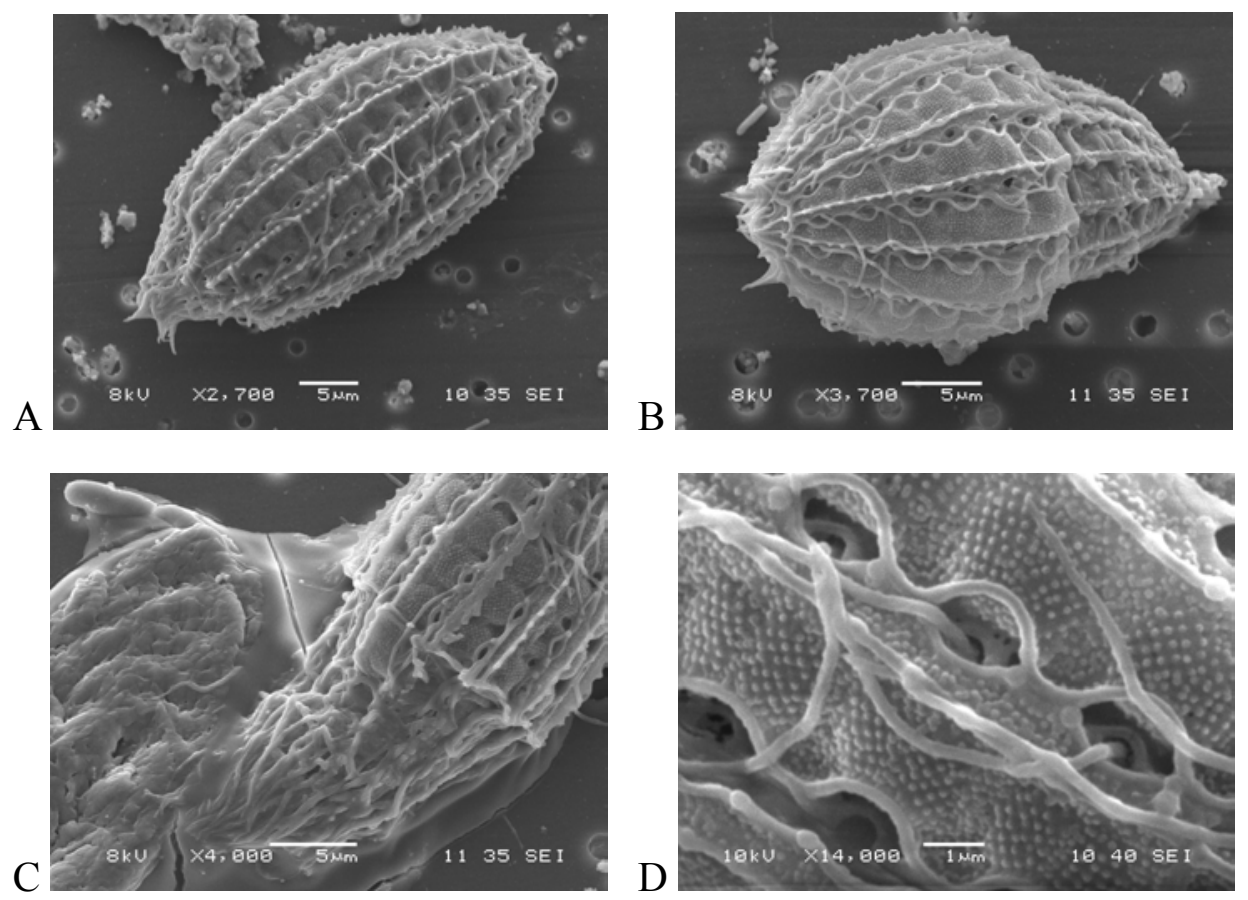

Figure 1: Scanning electron micrographs of Coleps morphology. $20 \mathrm{~mL}$ sample containing fish tank water was gravity fed through a poly-1-Lysine prepped Durapore Membrane filter followed by a $2.5 \%$ glut $/ 1 \% \mathrm{OsO}_{4}$ fix (using the filtrate as the solvent), water rinse and ethanol dehydration series; dried using HDMS and sputter coated with a gold flash palladium coating. A) Broad view of Coleps sample. Scale bar $5 \mu \mathrm{m}$. B) Micrograph of Coleps after dividing. Scale bar $5 \mu \mathrm{m}$. C) Coleps cell in process of division. Scale bar $5 \mu \mathrm{m}$. D) View of Coleps test and interwoven cilia. Scale bar $1 \mu \mathrm{m}$. 